\title{
The Teacher-Leader's Image: Between Personal Characteristics and Strategies Empowering Learners
}

\author{
Yonit Nissim ${ }^{1} \&$ Eitan Simon ${ }^{1}$ \\ ${ }^{1}$ Faculty of Education, Ohalo Academic College, Israel \\ Correspondence: Yonit Nissim, Faculty of Education, Ohalo Academic College, Israel. E-mail: \\ yonitn@ohalo.ac.il
}

Received: March 27, 2019

Accepted: April 25, 2019 Online Published: May 20, 2019

doi:10.5539/jel.v8n3p136

URL: https://doi.org/10.5539/jel.v8n3p136

\begin{abstract}
The present article aims to throw some light and clarify the image of the "teacher leader" as it is seen from the viewpoint of graduates and trainees in the M. Ed. program at the Ohalo Academic College. This research offers a porthole through which it is possible to observe their future role. The main research questions examined (1) How is the image of the teacher-leader visualized by the research's population? (2) What is the desired image of the teacher-leader as described by the respondents? Which leadership traits are seen by the respondents as the most dominant/meaningful? (3) Is there a difference between the respondents' perception of the term "teacher-leader" and their perception of the term "teacher"? (4) Is it possible to identify a main pattern that emerges from the analysis of all the respondents' answers to the statements and the open-ended questions?

The responses to the research questions were derived from mixed method data collection and analysis. The research instrument was a validated questionnaire that was distributed to graduates and trainees in the studied program $(\mathrm{N}=137) .54$ questionnaires were completed.

The main findings indicate that all the indices investigated in the quantitative part of the questionnaire, received high grades. Thus, the image of the teacher-leader is described as an exalted role, with distinguished characteristics and especially personal relations with pupils and their staff. The mean personal relationship index was the characteristic that received the highest grades (4.76). The reliability of the indices, as measured by Cronbach's $\alpha(\alpha=0.853)$ was found to be very high. In the qualitative part of the questionnaire, respondents were asked to conduct a deep observation and express it in their own authentic words: the respondents" "voice". Analysis of the responses found that the most dominant categories related to the index of personal characteristics (49) in relation to the "teacher-leader" and the teacher. Two main axes were identified from the processing of the different findings: a high level for the index of interpersonal relations with pupils and colleagues, and the central position of personal characteristics. In short, analysis of all the findings identified that there was a main trend whereby the graduates and trainees of the program see the image of the teacher-leader as holding distinct personality traits for leadership. These characteristics were translated in practice into strategies for educational work that could empower pupils, which would be expressed in improved learning achievements.
\end{abstract}

Keywords: teacher-leader, leadership, education

\section{Introduction}

\subsection{Theoretical Background}

The present era has witnessed a growing recognition that teacher's professional influence are critical components in the school's system improvement (Harris \& Jones, 2019). Looking across the landscape of U.S. schools, there are numerous models for supporting teacher leadership, but there is scant evidence about whether any of them make a difference for students (Wenner \& Campbell, 2017). In this sense there is ample room for dealing with the question of teacher leadership. A leader is not born a leader, rather a leader is created. The issue of leadership has been intensively researched but it still remains puzzling and far from being fully understood.

Teacher leadership is often defined as a "set of practices that enhance the teaching profession". States and districts are leveraging teacher leadership in multiple ways to professionalize teaching, create opportunities for teacher career advancement, facilitate school improvement, and facilitate professional learning for educator and student success. By proposing a set of questions to consider rather than the answers to those important issues. 
Educational leaders have a significant influence. The way in which they demonstrate their leadership and shape the educational staff radiates on and influences learning achievements in school. However, their influence is felt through the activities of others who act under their inspiration, especially the teachers who mediate between the leaders and school outputs (Oplatka, 2015). Leaders need to have: knowledge, experience, commitment, patience and above all negotiating skills and the ability to work with others in order to achieve goals. Jenkins (2013) notes that the foundation for good leadership is commitment to the organization without egoism. This is especially so in an educational organization. Jenkins notes that although leadership has been widely studied, it remains puzzling and far from well-understood. The present study was inspired by this insight. In addition to the enigmatic nature of the term "leadership", we believe that the modern world demands the construction of new conceptualizations suitable for the present era and the continuation of research on the subject that has not yet been exhausted.

The position of leadership, its definitions and implications have undergone alterations over the time axis including approaches that dealt with the field of educational leadership in the daily world of teachers and this necessarily affects students training for management in different educational areas. Several studies have investigated the issue of "who is a good teacher?" also "are teachers all leaders?" And how can educational leadership be created among tomorrow's teachers. One of the scholarly works that attempted to answer these questions was a document published in 2011, the product of the work of a forum of educators, which attempted to construct a model setting standards for the image of a teacher-leader (Teacher Leadership Exploratory Consortium, 2011). The document defined teacher leadership as "the process by which teachers...influence their colleagues, principals, and other members of the school community to improve teaching and learning practices with the aim of increased student learning and achievement." This model establishes several significant categories for the teacher leader, including: collaboration, distribution of high-quality practices, taking action, constituting a model for imitation, serving in a formal role.

\subsection{Leadership}

There are many and sometimes conflicting definitions of leadership in the professional literature, which have attempted to capture the substance of this concept and its characteristics in words (Levy, 2008). Leadership consists of "a complex of features and activity, primarily involving the setting of goals, the definition of a vision and its realization and the guidance of others to reach common goals. Leadership is defined as an act of interaction between the leader and those they lead. Educational leadership has unique characteristics including the ability to shape and instill a vision, to encourage learning, to build cooperation and shared construction of meaning and knowledge, creating opportunities for creativity and development, mediating knowledge, open to ideas, disseminating perceptions and values, implementing beliefs and values, using beliefs and information, structuring continuous dialog, developing new ideas though management of reflective processes in a shared and up-to-date moral climate". An educational leader in contrast to leaders in other fields have the ability to use pedagogic-strategic and not only strategic discretion. In other words, they can define educational goals and adapt educational means to suit the predetermined goal (Harpaz, 2009). Additionally, educational leaders have a conscious and coherent educational identity. Given this identity, the leader can define the educational goal and fit their tools to that goal (Eyal, 2014). As noted, there have been attempts to describe a model that sets out standards for the image of the teacher-leader (Teacher Leadership Exploratory Consortium, 2011).

\subsection{Educational Leadership}

There are three main approaches towards the definition of "educational leadership". The first "the knowledge approach" sees the educational leader as a person with knowledge concerning leadership of the education framework, with appropriate skills to lead processes. However, knowledge alone is insufficient to be able to lead educational institutions. The second approach "the characteristics approach" emphasizes the educational leader's characteristics such as: honesty, balance, innovation etc. In contrast to information, characteristics are more personal and distinguish the educational leader. The third approach looks at "identity" especially the individual's pedagogic identity. An educational leader has an educational goal anchored in their educational worldview. Their pedagogic-strategic discretion is guided by this worldview (Harpaz, 2009). Eyal (2014) notes that there is no single approach suitable for an educational leader, rather they need to integrate all three approaches in the appropriate amount, according to the setting in which they act as leaders. The next section details the issue of teachers' leadership, an issue that stands at the heart of the present study.

Although there has been much occupation with the issue of leadership in general, and the issue of educational leadership in particular for many years, there are still significant hidden layers of this issue which remain to be investigated. Simon and Tami (2014) dealt with this issue from the aspect of adaptation of leadership style to the 
discipline being taught. It was seen that the management style is indeed characterized by the discipline to which teaching trainees are trained. Kadosh and Rozenthal (2014) argued that despite the fact that a considerable research foundation indicates that teacher-pupil relations are the most important factor in educational processes, very few studies provide deep and focused clarification on this factor.

Broadly speaking, educational change, including teacher education change, is undoubtedly multi-faceted, uncertain; it takes time, skilled leadership The purpose of the present study is to throw some light on this issue through the investigative reflective observation of graduates and trainees in a masters' degree course in Management and Organization of Education systems concerning the place of personal relations in the image of the teacher leader.

\subsection{The Teacher Leader}

Teachers as leaders integrate and assist learning, they guide the group processes by providing optimal consideration to the pupils and to the learning contents. They believe in the possibility of this combination and simultaneously transmit this to their pupils (Cohen, 2011). While according to Darom (2003) the profession of teaching is one of the most difficult and complex professions: "it does not only demand much responsibility, professionalism and characteristics such as sensitivity, empathy, leadership and rhetorical skills, but it also includes the fulfilment of many different functions". The features that shape the teachers' world indicate "that the teacher is, at least formally, the leader in the classroom". This is because the teacher is not selected by the prior consent of the pupils, but by the virtue of an external appointment by an authoritarian body (Darom, 2003). The educational leader is often associated to the conductor of an orchestra who organizes, diagnoses and encourages communication with appropriate timing to form a final perfect composition. Shatz-Oppenheimer (2006) defined a flexible teacher as one who reacts and adapts themselves to learners in the heterogenous class while realizing equal educational opportunities. Thus, teaching develops and grows from pupils' reactions and their personal worlds and personalities. Cohen (2011) also describes how the figure of the teacher-leadershould be characterized: "the teacher is a figure for imitation, a charismatic person with knowledge and a vision. [He is characterized by four main elements] charisma, personal relations, posing intellectual challenges and setting a vision for the pupils- either by their image or by setting concrete aims beyond the personal goal of each pupil". As noted, the present study aimed to clarify the attitudes of graduates of and trainees in a master's program on Management and Organization of Education Systems in the Ohalo Academic College, towards the image of the teacher leader.

\section{Method}

\subsection{The Research Goal}

To examine the image of the teacher-leader as described in the attitudes and perceptions of future education leaders who were undergoing training or had completed their studies for a master's degree in Administration and Management of Education Systems.

\subsection{The Research Method}

The research employed mixed qualitative and quantitative methods, using field-grounded theory and quantitative methods as appropriate, including several statistical tests. The mixed methods approach was chosen carefully assuming that there was a certain in-built tension between the two methods (qualitative and quantitative), representing the gap between the neutral quantitative scoring and the qualitative expression of personal voices.

\subsection{Data Processing}

Data processing was conducted with the aid of SPSS software. At the first stage descriptive statistical indices were calculated and the reliability of the questionnaires was tested. At the second stage, to test the first research question, one-directional ANOVA tests were performed.

As noted, the research adopted mixed methods including statistical data processing for the quantitative part of the questionnaire and content analysis was applied to the completion of sentences in the open-ended questions part. In the quantitative part, at the first stage, main categories were identified that emerged from the respondents' responses, and at the second stage the number of answers in each category were counted and the findings were presented in a frequencies table. At the second stage the different categories were sorted into four main indices, and this was also performed for the quantitative data. Thus too, words were counted to find the dominance of key words (using Atlas software). 


\subsection{The Research Process}

A questionnaire was constructed and underwent apparent validation by three expert lecturers, each with a doctorate in education. A one-stage comfort sample was selected. The questionnaire was distributed through Google. Drive online to the entire list of graduates of the program and to those in training at the time in the master's degree Administration and Management of Education Systems course $(\mathrm{N}=137$ students). 54 respondents agreed to complete the questionnaire. Responses were anonymous. The research procedure included the collection of data, statistical analysis and processing, formation of findings and presentation of statistics and deductions, from which conclusions and insights were drawn and finally it was possible to answer the research questions in a discussion and summary.

\subsection{The Research Tools}

The research employed a questionnaire divided into three parts: (A) socio-demographic data. (B) 15 statements for which the respondents were asked to grade their level of agreement on a Likert scale of $1-5$. The statements were divided into four indices: personal relationship, pupil empowerment, personal characteristics and role characteristics that typify the image of the "teacher-leader". (C) Completion of sentences with free text, allowing the respondents to express their authentic "voice". The qualitative data collected from Part C were analyzed with first and second cycle coding and categories were formed from the analyzed data.

\subsection{The Research Questions}

1) How is the image of the teacher-leader visualized by the trainees and graduates of the master's degree program in Administration and Management of Education Systems?

2) What is the desired image of the teacher-leader as described by the respondents? Which leadership traits are seen by the respondents as the most dominant/meaningful?

3) Is there a difference between the respondents' perception of the term "teacher-leader" and their perception of the term "teacher"?

4) Is it possible to identify a main pattern that emerges from the analysis of all the respondents' answers to the statements and the open-ended questions?

\subsection{The Research Population}

54 students and graduates from the master's degree course in Administration and Management of Education Systems.

\section{Results}

\subsection{The Research Population}

Fifty-four current students and graduates of the master's program in Management and Organization of Education Systems participated in the research. Thirty-seven of them (68.5\%) were women and 17 men (31.5\%). Most of the respondents were graduates (70.4\%) and the rest were currently students in Year $1(22.2 \%)$ or in Year 2 (7.4\%). Respondents' ages ranged from 29-61 years with a mean of 45.09 (S.D.=8.32). Table 1 displays the distribution of the respondents according to these demographic variables.

Table 1. Distribution and central indices of the respondents' demographic variables $(\mathrm{N}=54)$

\begin{tabular}{lllllll}
\hline Variable & $\mathrm{N}$ & $\%$ & Minimum & Maximum & Mean & S.D. \\
\hline Age & & & 29 & 61 & 45.09 & 8.32 \\
Gender & & & & & \\
Male & 17 & $31.5 \%$ & & & \\
Female & 37 & $68.5 \%$ & & & \\
Stage of studies in the master's program & & & \\
Year 1 & 12 & $22.2 \%$ & & & \\
Year 2 & 4 & $7.4 \%$ & & & \\
Graduates & 38 & $70.4 \%$ & & & & \\
\hline
\end{tabular}

\subsection{The Research Tools}

The respondents answered a questionnaire including 15 statements that tested their opinions regarding the "teacher leader". These statements were sorted according to four subjects: personal relations (Statements 2 and 3), pupil empowerment (Statements 1, 5 and 6), personal characteristics (Statements 4, 10, 12, 13 and 15) and role characteristics Statements 7, 8, 9, 11 and 14). The statements were graded on a 5-point Likert scale $(1=$ not 
at all to 5 to a large extent). The mean of the grades given by the respondents was calculated for each subject and in this way the four research indices were defined.

Table 2 below displays the characteristics of the indices, general means and standard deviations ad also their measured reliability.

Table 2. General characteristics, means, S.D.s and reliability of the research indices $(\mathrm{N}=45)$

\begin{tabular}{llllllll}
\hline Index & Statement no. & Scale & Minimum & Maximum & Mean & S.D. & $\boldsymbol{\alpha}$ \\
\hline Personal relations & 2 & $1-5$ & 3.00 & 5.00 & 4.76 & 0.43 & 0.798 \\
Pupil empowerment & 3 & $1-5$ & 2.67 & 5.00 & 4.55 & 0.48 & 0.663 \\
Personal characteristics & 5 & $1-5$ & 3.00 & 5.00 & 4.68 & 0.43 & 0.853 \\
Role characteristics & 6 & $1-5$ & 3.00 & 5.00 & 4.60 & 0.41 & 0.731 \\
\hline
\end{tabular}

The highest mean grade was given for the personal relations index (4.76). This finding indicates very high levels of considerate relations and mutual trust relations demonstrated by the teacher-leader towards their pupils. The second highest mean was given to personal characteristics (4.68) and this was followed by the mean for role characteristics (4.60). The mean for pupil empowerment was the lowest, but still relatively high (4.55). The reliability of the indices, as measured by Cronbach's $\alpha$ were found to be high (especially the personal characteristics index), a finding that characterizes a high level of consistency and stability for each of the statements. The findings indices are shown in Figure 1.

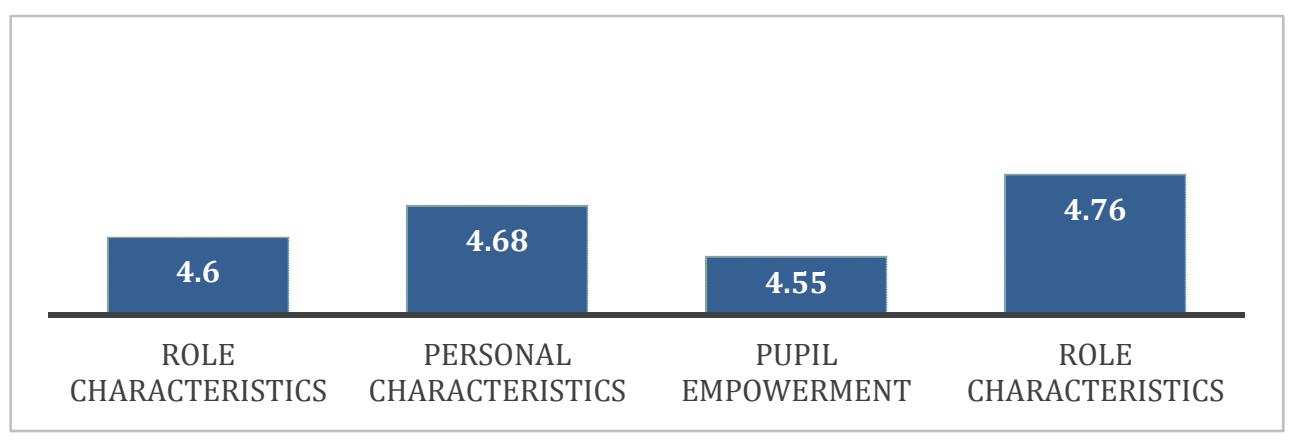

Figure 1. Findings for the indices of the teacher-leader questionnaire

Table 3 below displays the means of the respondents' grading for all the questionnaire statements.

Table 3. Means and standard deviations for the teacher-leader questionnaire statements $(\mathrm{N}=54)$

\begin{tabular}{|c|c|c|c|c|}
\hline The teacher leader & Minimum & Maximum & Mean & SD \\
\hline Enables free choice and a broad range of activity for pupils & 2 & 5 & 4.20 & 0.74 \\
\hline Demonstrates consideration and respect for pupils & 3 & 5 & 4.74 & 0.49 \\
\hline Creates a system of mutual trust with pupils & 3 & 5 & 4.78 & 0.46 \\
\hline Transcends personal interests & 3 & 5 & 4.46 & 0.69 \\
\hline Encourages pupils to take responsibility for themselves & 2 & 5 & 4.72 & 0.60 \\
\hline Stimulates pupils' motivation to learn & 3 & 5 & 4.72 & 0.49 \\
\hline Able to respond to new problems outside their experience & 3 & 5 & 4.43 & 0.64 \\
\hline A leading figure oriented towards the pupils & 3 & 5 & 4.81 & 0.44 \\
\hline Not afraid of challenges & 3 & 5 & 4.64 & 0.56 \\
\hline Charismatic & 3 & 5 & 4.70 & 0.50 \\
\hline Functions well even under pressure & 3 & 5 & 4.65 & 0.55 \\
\hline Serves as a personal example for the pupils in the school framework & 3 & 5 & 4.81 & 0.44 \\
\hline Self-confident & 3 & 5 & 4.67 & 0.55 \\
\hline Flexible character, can function in extreme conditions & 2 & 5 & 4.47 & 0.75 \\
\hline Has the ability and willingness to influence others & 3 & 5 & 4.74 & 0.48 \\
\hline
\end{tabular}


Given the data that appears in Table 3, it is obvious that according to all the respondents, the teacher-leader primarily serves as a personal model for pupils in the school (4.81), a leading figure, oriented towards the pupils. Moreover, it appears that the respondents feel that the less strong skills of the teacher-leader are "facilitating freedom of choice and a broad field of action for the pupils" (4.20).

In order to distinguish whether there are correlations or differences between the research indices according to the different demographic variables, statistical tests were conducted as follows:

\subsection{Correlation with Gender}

In order to examine whether there are differences between the opinions of males and those of females regarding the indices describing the teacher leader, t-tests were performed for the independent variables. Table 4 below shows the means among the two groups and the results of these tests.

Table 4. Differences between males and females regarding the indices for the teacher leaders and results of t-tests

\begin{tabular}{|c|c|c|c|c|c|}
\hline \multirow[t]{2}{*}{ Index } & \multicolumn{2}{|c|}{ Males $(\mathrm{N}=17)$} & \multicolumn{2}{|c|}{ Females $(\mathrm{N}=37)$} & \multirow[t]{2}{*}{ t-test } \\
\hline & Mean & S.D. & Mean & S.D. & \\
\hline Personal relations & 4.82 & 0.30 & 4.73 & 0.48 & 0.74 \\
\hline Pupils empowerment & 4.49 & 0.44 & 4.58 & 0.49 & 0.62 \\
\hline Personal characteristics & 4.76 & 0.32 & 4.64 & 0.47 & 1.01 \\
\hline Role characteristics & 4.60 & 0.29 & 4.60 & 0.46 & 0.01 \\
\hline
\end{tabular}

As can be seen from the data in Table 4, no significant differences were found between the opinions of males and females concerning the four indices for the teacher leader.

\subsection{Correlation with Year of Academic Studies}

In order to discover whether there was a difference in gradings for the indices for the teacher-leader between respondents currently studying the course (Years 1 and 2) and those who were in more advanced stages of learning (Year 3 and graduates), t-tests were performed for additional independent variables. Table 5 below presents the means for the two groups and the results of the t-tests.

Table 5. Differences according to stage of academic studies for the indices for the teacher-leader and results of t-tests

\begin{tabular}{llllll}
\hline \multirow{2}{*}{ Index } & \multicolumn{2}{l}{ Early stage studies $(\mathbf{N}=\mathbf{1 6})$} & \multicolumn{2}{l}{ Later stage studies (N=38) } & \multirow{2}{*}{ t-test } \\
\cline { 2 - 5 } & Mean & S.D. & Mean & S.D. & \\
\hline Personal relations & 4.66 & 0.60 & 4.80 & 0.34 & 0.92 \\
Pupils empowerment & 4.44 & 0.59 & 4.60 & 0.42 & 1.12 \\
Personal characteristics & 4.60 & 0.56 & 4.71 & 0.37 & 0.86 \\
Role characteristics & 4.59 & 0.50 & 4.61 & 0.38 & 0.11 \\
\hline
\end{tabular}

As can be seen from Table 5, there were no significant differences by stage of studies regarding the marking for different indices. Nevertheless, there was a slight increase in the marking of the indices which was influenced by more years of study. It is possible that academic studies had a slight influence on the reinforcement of the teacher leader's image.

\subsection{Correlation with Age}

In order to examine whether there is a correlation between the indices and the respondents' ages, Pearson correlation coefficients were calculated. Table 6 shows the results of these tests.

Table 6. Pearson correlation coefficients to test correlation between the research indices and age

Note. $*-\mathrm{p}<0.05$.

\begin{tabular}{ll}
\hline Index & Age \\
\hline Personal relations & $0.285^{*}$ \\
Pupils empowerment & 0.241 \\
Personal characteristics & 0.204 \\
Role characteristics & 0.148 \\
\hline
\end{tabular}


A low-level but significant positive correlation was found: $r=0.285, p>0.05$, between the respondent's opinion concerning the teacher-leaderand the respondent's age, in such a manner that insofar as the respondent was older then their opinion concerning the personal relations of the teacher-leader would be more positive. The other correlations were also found to be positive but not significantly so.

\subsection{Analysis of the Qualitative Data}

\section{Verbal findings}

The qualitative data were used to examine the respondents' opinions in more depth, to express their "authentic voice". The respondents were asked to complete five sentences in this part of the questionnaire:

1) Leadership is .........

2) A good teacher is .........

3) I would like to be a teacher, who ........

4) My goal as a teacher is ........

5) In my view, educational leadership is ........

In this way the respondents were able to express their thoughts and feelings. At the first stage, their answers were read several times. Then main categories were identified and encoded as they emerged from the respondents' answers. At the next stage, the answers in each category were counted and the findings were presented in a frequencies table. At the third stage, the different categories were sorted into the four main indices (as performed at the first quantitative stage). At the fourth stage, secondary division was performed for the perception of the term "teacher leader" (sentence 1) and for the perception of the term "teacher" (sentences 2-4). Table 7 below displays the results of these analyses.

Table 7. Analysis of the content categories

\begin{tabular}{|c|c|c|c|c|c|}
\hline Index & $\begin{array}{l}\text { Leadership } \\
\text { is ........ }\end{array}$ & $\begin{array}{l}\text { A good teacher } \\
\text { is ... }\end{array}$ & $\begin{array}{l}\text { I would like to be a } \\
\text { teacher, who ........ }\end{array}$ & $\begin{array}{l}\text { My goal as a teacher } \\
\text { is ... }\end{array}$ & $\begin{array}{l}\text { In my view, educational } \\
\text { leadership is . . . . . }\end{array}$ \\
\hline Personal relations & 6 & 1 & 2 & 3 & 5 \\
\hline Pupils empowerment & 1 & 14 & 8 & 18 & 17 \\
\hline Personal characteristics & 23 & 18 & 4 & 4 & 19 \\
\hline Role characteristics & 9 & 1 & 3 & 14 & 6 \\
\hline
\end{tabular}

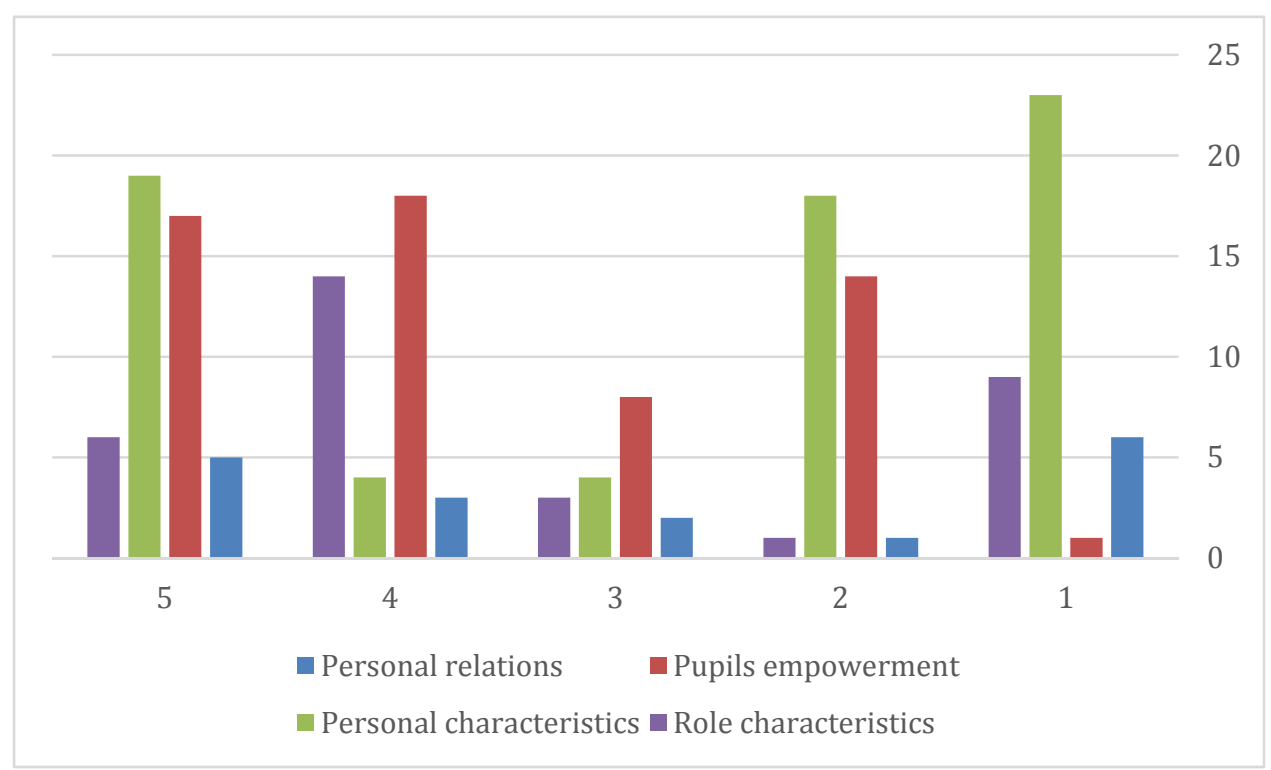

Figure 2. The image of the teacher-leader according to four indices 
The content analysis indicated that the category that received the most mentions in the sentence completion related to personal characteristics (49 mentions). This was followed by pupil empowerment (41 mentions), role characteristics (27) and personal relations (12). The content analysis clearly showed two dominant indices in the answers: personal characteristics and pupil empowerment.

It was found that a synthesis was formed between the teacher's personal characteristics and the teacher leader, and the way in which the teacher-leaders harnessed to benefit pupil empowerment. These two subjects were clearly predominant in many of the completed sentences, for example:

"In my view, leadership is guiding the pupils to be independent and to take responsibility so that they can continue with their own strengths".

"Leadership guides the system/staff/pupils to a meaningful educational perspective that enables their empowerment, curiosity, learning, flexibility and creativity".

Other examples drew a connection between the different characteristics of the teacher-leader as a person who influences and shapes the educational climate and motivates pupils to succeed:

"influences the educational climate throughout the organization, influencing the teachers and pupils in all areas".

"Improves motivation among the pupils and teachers in order to motivate them to succeed".

"empowering, educating to values, instilling the subject in the pupils, in their colleagues and creating learning practices with emphasis on values according to which they will operate in the present and in the future".

"leading to a society of excellence with unique values and skills".

"leading the pupil to personal success".

"leading the pupils to realize their inherent potential".

In other words, the ability of the teacher to lead is presented as a characteristic translated into a strategy that assists the promotion and shaping of the pupils. From the analysis of all the answers to the statements and the completion of the sentences a pattern emerges according to which: the teacher-leader has leading personality characteristics to assist pupil empowerment.

At the next stage the text was analyzed with the help of Atlas software, in the attempt to identify key words and frequently mentioned expressions that were repeated in the completion of the sentence "leadership is ...". The repetitive answers used the words: "leads" (23), "responsibility" (6), "to motivate" (4), "charisma" (4). Analysis of all the respondents' answers yielded a picture of leadership as including abilities to lead, and ability to captivate others, and different personal characteristics: charisma and responsibility. This finding is in line with the characterization of the image of a teacher-leader as one who is epitomized by certain personal characteristics and strategic abilities.

The approach of Cohen (2011) indicates that the image of the teacher-leadershould be characterized as a model for imitation, a charismatic individual with knowledge and a vision. This person is seen as having four main properties: charisma, personal relations, providing intellectual challenges and setting a vision for the pupil, and setting concrete goals beyond the personal goals of each pupil. In other words, the teacher-leader uses their abilities and characteristics to establish a system that empowers and challenges their pupils. Moreover, this complies with a model that sets standards for the teacher-leader based on the Teacher Model Standard (Teacher Leadership Exploratory Consortium, 2011), including influence - teaching and learning practices - pupil empowerment to improve achievements.

\subsection{Associations and Metaphors for the Teacher Leader}

In this part of the questionnaire the respondents were asked to provide words that they closely associate with the term "leader". In the analysis of the answers many respondents likened the leader to well-known canonical characters, for example: Moses (7), the Pied Piper of Hamlin (2) or likened the leader to a captain, a lighthouse, an arrowhead or the Lion King.

There were two metaphorical expressions clearly creating an allegory that illustrated leadership: "leadership is like a stone statue. Insofar as the artist invests more in the small details, then the statue will be more realistic, closer to reality". Another respondent described the leader as: "a sun that sends its pleasant rays in all directions". It is important to remember that each associative word is founded on thought, however, it is noted that very few of the respondents answered with metaphorical expressions. Most of the respondents chose to provide one-word answers, resembling an image that for them represented the ultimate leader. 


\section{Summary and Discussion}

The purpose of the research was to investigate the image of the "teacher-leader" as reflected in the eyes of future educational leaders who had completed or were in the process of training for a master's degree in Administration and Organization of Education Systems.

The main research questions discussed the way in which the respondents characterized the teacher-leader, relying on four indices, and also on free textual expression of their opinions. In response to the first research question: "What is the optimal image of the teacher-leader as perceived by trainees studying in the Administration and Organization of Education Systems master's degree program?" it was found that the mean grade given to the personal relations index was 4.76, all the respondents granted this index the highest grades of all four examined indices. This finding represents a very high extent of considerate relations demonstrated by the teacher-leader towards their pupils. The second highest mean was for the index of personal characteristics (4.68) and this was followed by the mean for role characteristics (4.60). The mean grade for the index pupil empowerment was the lowest, but still received a relatively high level (4.55). It is noted that all the studied indices received very high grades. This indicates respect for the concept "teacher-leader" and the students and graduates of the master's degree program seem to perceive this role as an exalted role with high level personal and role characteristics and the use of strong behavioral strategies, a desirable and ideal role. It was also found that there is a positive low level but significant correlation between the respondent's opinion concerning the teacher-leader and the respondent's age $(r=0.285, p>0.05)$, so that insofar as the respondent is older then their opinion concerning the teacher-leader's personal relation will be more positive. The respondents felt that the teacher-leader should provide a personal example to their pupils in the school (4.81) and constitute a leading figure that guides the pupils (4.81). An additional finding indicates that the less strong skills of the teacher-leader relate to the index that received the lowest mean grade (4.20) regarding the provision of free choice and a broad range of activity for the pupils. These findings are supported by the theoretical approach described by Oplatka (2015), who argues that "people-orientation includes leadership behavior that aims to create social cohesion, trust, warmth, interest and respect in the relationships between the leader and their subordinates. Task-oriented behavior is also referred to as initiation (including leadership behavior that creates defined practices of work organization, communication channels and work methods". Oplatka continues "[in] the relationship of leader-subordinates. This means the quality of relations between the leader and their group, this includes an extent of safety, trust and respect that the leader provides for their subordinates, and they for him. The assumption is that respect and admiration for the leader reinforce their influence and power in the group" (Oplatka, 2015)

In response to the research questions which aimed to investigate what would be the desirable image of the teacher-leader in the respondents' view: "Which leadership characteristics are most dominant or meaningful in the respondents' eyes?" The variance in perception between the two concepts "teacher" and "leader" was based on the distinction between leadership abilities (of the teacher-leader) and pedagogic educational abilities (of the teacher). Moreover, it is obvious that the respondents saw the image of the teacher-leader as one that grows out of pedagogy and education, through the growth of the "teacher". The image of the teacher-leader that emerges from all the findings creates their view of a synthesis between leadership motivating there and charisma that characterize leaders of all kinds, and the influence and channeling of these characteristics for the benefit of the relationship with the pupil as a contribution to their empowerment, expressed in their achievements.

In answer to the research question "Is it possible to identify a main practice that emerges from the analysis of all the collected data?" the responses represented an "axis" ranging from inner personal characteristics to external behavioral strategies. In other words, personal and role characteristics lead to interpersonal relations that can contribute to pupil empowerment. The teacher's ability to lead is presented as a characteristic translated into a strategy that assists pupils' advancement and development.

Analysis of all the statements and responses yielded the respondents' image of the teacher-leader as follows: The teacher-leader has personal characteristics that assist the pupils' empowerment. This description corresponds with various approaches described in the research literature in this field, especially the approach that stresses that the teacher-leader assists learning by combining the guiding of group processes and optimal consideration both for the pupils and the learning contents. They believe in the possibility of this combination and at the same time radiates this belief to their pupils (Cohen, 2011). Cohen even defines the image of the teacher-leader: "the teacher is a figure for imitation, a charismatic person, with knowledge and a vision. They are characterized by four main elements: charisma, personal relations, intellectual challenge and the setting of a vision for the pupil—whether in their image or by setting concrete aims beyond the individual goal of each pupil" (Cohen, 2011). 
Analysis of the qualitative data provided a deeper insight into the findings that emerged from the quantitative data, which were more "sterile" regarding the desirable and ideal image of the teacher-leader. As described above the quantitative data produced very high grades reflecting much respect for the teacher-leader by the respondents. The qualitative data produced a freer, authentic, personal and subjective description of the respondents' opinions. It can be assumed that the independent writing represented less theoretical reflection about themselves, their work and beliefs, describing what really exists and less what was desirable and sought after. This could explain the gap in grades between the different content categories.

Additionally, the text analysis (using Atlas software) used to search for key words, yielded answers that together put together a puzzle indicating that leadership includes: the ability to lead, ability to draw others after them, charisma and responsibility. This finding is in line with the characteristics of the image of the teacher-leader as one who is represented by certain personal characteristics (charisma and responsibility) and strategic abilities (the ability to lead other, goals and task-oriented and to draw others after them). As already noted above, Cohen (2011) notes that the image of the teacher-leader "is a figure for imitation, a charismatic person with knowledge and a vision. [He is characterized by four main elements] charisma, personal relations, posing intellectual challenges and setting a vision for the pupils - either by their image or by setting concrete aims beyond the personal goal of each pupil". In other words, the teacher-leader uses their abilities and other characteristics to establish an empowering and challenging environment for their pupils. These findings to some extent reflect the description of the model which sets standards for the teacher-leader. This model, detailed in the Teacher Leader Model Standard (Teacher Leadership Exploratory Consortium, 2011) envisages the teacher-leader's influence on teaching and learning, leading to pupil empowerment, expressed in the improvement of pupil achievements. In our opinion, there is a tension in the findings and a gap between the responses to the different (quantitative and qualitative) questionnaires. This indicates a difference between the respondents' perceptions of the "teacher" image and the "teacher-leader" image. Analysis of the findings clearly shows that the graduates and trainees prepared for the role of administration and organization of education systems have a differential view of the "teacher-leader" in contrast to their view of the "teacher". While the teacher is characterized by direct interaction that influences pupil empowerment, the model of the leader is characterized as having personal and role characteristics that place them above the "teacher".

To summarize: unification of all the above-described findings, enabled a conclusion that the research respondents see the "teacher-leader" as an image that points up a gap between what exists in practice and what is desirable, between the "teacher" and the "leader". Tension exists on the axis between "internal and external" and between "personal characteristics" and their expression in practice as "strategies". This is the traditional view of practice according to old approaches.

The internal dimension is represented by: a set of personal and role characteristics that can be translated into actions, behavior, a vision, leading and establishing personal relations that contribute to the pupil's empowerment in different dimensions (learning, achievements, development, growth etc.). This approach is reinforced by additional definitions which claim that: "leadership is a complex of characteristics and behaviors which principally include the setting of goals, definition of a vision and its realization and leading other people to a common goal. Leadership is defined as an interactive act between the leader and their subordinates. Educational leadership Educational leadership has unique characteristics including the ability to shape and instill a vision, to encourage learning, to build cooperation and shared construction of meaning and knowledge, creating opportunities for creativity and development, mediating knowledge, open to ideas, disseminating perceptions and values, implementing beliefs and values, using beliefs and information, structuring continuous dialog, developing new ideas though management of reflective processes in a shared and up-to-date moral climate" (Schneider, 2013).

\section{Recommendations}

It is recommended that teacher and educational leadership training should emphasize and guide future teachers and educational leaders on the basis of approaches and strategies that are expected from the teacher-leader. In other words, the gap between what exists and what is desirable should be reduced with appropriate training that is more focused on leadership practices.

It is suggested that teacher and educational leader training should emphasize and imbibe different skills such as: collaboration, team work, sharing of teaching successes and successful practices, taking action, undertaking roles within the educational institution. The aim is to create training processes that will produce graduate who will become teacher-leaders and practice the model of the teacher-leader, who realizes that educational leadership involves: the way in which teachers influence their colleagues, principals and other stakeholders in the school community to improve teaching and learning practices in order to improve their pupils' achievements. The 
proposed model sets out several meaningful categories for the teacher-leader, including: collaboration, sharing high-quality practices, taking action, constituting a model for imitation, serving in a formal role.

\subsection{Recommendations for Follow-Up Research}

Further research should examine the relation between the teacher-leader and pupil achievements in the same research population. The boundaries of the research should also be widened to other teacher training institutions and education managers.

\subsection{Limitations of This Research}

The research relied on a comfort sample including all the students and graduates of a master's degree program in Administration and Organization of Education Systems. Fifty-four of those approached replied to the questionnaires. A broader sample could have produced different results. The present study was conducted in a peripheral academic college (the college is in Katzrin in the Golan Heights) with unique features than differ from those of other colleges and universities in different areas of Israel.

\section{References}

Alma, H., \& Michelle, J. (2019). Teacher leadership and educational change. School Leadership \& Management, 39(2), 123-126. https://doi.org/10.1080/13632434.2019.1574964

Applewig, N., \& Washlo-Vigisar, I. (2010). The role of a teacher at the beginning of the 21 st century. Jerusalem: Van Leer Institute. [Hebrew]

Berg, J. H., Horn, P., Supovitz, J. A., \& Margolis, J. (2019). Typology of Teacher Leadership Programs. CPRE Research Reports. Retrieved from https://repository.upenn.edu/cpre_researchreports/109

Cohen, A. (2011). Teacher's perspectives: On teacher development and the leadership of principals aimed at improving teaching. Israel: Avney Rasha Center for Knowledge. [Hebrew]

Darom, D. (2003). A climate of growth. Bnei-Barak: Sifriat Poalim, Kibbutz Artzi Hashomer Hatzair. [Hebrew]

Eyal, L. (2014). A practical model for the shaping of the educator's professional identity as a leader promoting change. Mofet Institute Journal, 53, 44-50. [Hebrew]

Harpaz, I. (2009). Hey we're totally not in the right direction. Hed Hahinuch, 4, 82-87.

Kadosh, K., \& Rozenthal, Z. (July, 2014). The connection between teaching style and leadership style of the teacher and learning styles in matriculation exams among pupils studying in mainstream classes in contrast to pupils in strengthened classes. Studies in Education (new series), 9(10), 232-258. [Hebrew]

Levy, O. (2008). Management and leadership for change and innovation. Israel: Rimonim. [Hebrew]

Oplatka, I. (2015). Fundamentals of education management: Leadership and management in an educational organization. Israel: Pardess Publications Ltd. [Hebrew]

Teacher Leadership Exploratory Consortium. (2015). Teacher-leaderModel Standards. Retrieved from https://www.ets.org/s/education_topics/teaching_quality/pdf/teacher_leader_model_standards.pdf

Wenner, J. A., \& Campbell, T. (2017). The theoretical and empirical basis of teacher leadership: A review of the literature. Review of Educational Research, 87(1), 134-171. https://doi.org/10.3102/0034654316653478

\section{Copyrights}

Copyright for this article is retained by the author, with first publication rights granted to the journal.

This is an open-access article distributed under the terms and conditions of the Creative Commons Attribution license (http://creativecommons.org/licenses/by/4.0/). 